\title{
Association of IL-10 and TNF-a polymorphisms with risk and aggressiveness of hepatocellular carcinoma in patients with HCV-related cirrhosis
}

\author{
Ahmed Saleh ${ }^{1,2^{*}}$, Ahmed M. Saed $^{1}$ and Mostafa Mansour ${ }^{3}$
}

\begin{abstract}
Background: Hepatitis C virus (HCV) infection is a significant risk factor for cirrhosis and hepatocellular carcinoma (HCC) that carry a high mortality. The study aims to investigate the effect of tumour necrosis factor (TNF)-a and interleukin (IL)-10 polymorphisms on risk and pattern of HCC in patients with HCV-related cirrhosis.

Results: The mean age of the HCC group was $56.21 \pm 4.62$ years and $54.27 \pm 7.63$ years for the cirrhotic group. The GG genotype of TNF-a and TT genotype of IL-10 showed a higher incidence of HCC in comparison to the cirrhotic group with $P=0.01$ and 0.004 . On the calculation of the aggressiveness index (Agl), the $\Pi$ haplotype was significantly associated with more aggressive tumours in contrast to the other haplotypes with $P<0.001$. There is a significant association of portal vein thrombosis, ascites and high Agl with the GG haplotype in contrast to the other haplotypes with $P=0.002,0.029$ and $<0.001$, respectively, as regards TNF-a. High Agl (C) was associated with the $\Pi T$ haplotype of IL-10 and GG haplotype of TNF-a.

Conclusion: Our data bring an essential association of IL-10 and TNF polymorphism with the occurrence of HCC in patients with HCV-related liver cirrhosis. The GG haplotype of TNF- $\mathrm{a}$ and TT/AT haplotype of IL-10 are associated with the more aggressive pattern of HCC, so those patients must be treated as early as possible.
\end{abstract}

Keywords: Interleukin, Tumour necrosis factor, Hepatocellular carcinoma

\section{Background}

Hepatitis $\mathrm{C}$ virus (HCV) and hepatitis B virus (HBV) infections are global health problems as they are associated with high morbidity and mortality. It is estimated that about 200 million people are infected with HCV, among which 170 million are chronically infected [1].

Hepatocellular carcinoma (HCC) is the fifth most common cancer and the third cause of cancer-related deaths worldwide [2]. More than 600,000 people die

\footnotetext{
* Correspondence: drahmedsaleh1981@gmail.com

'Department of Internal Medicine, Hepatology \& Gastroenterology unit,

Faculty of Medicine, Mansoura University, Mansoura, Egypt

${ }^{2}$ Specialized Medical Hospital, Faculty of Medicine, Mansoura University,

Mansoura, Egypt

Full list of author information is available at the end of the article
}

from HCC each year [3]. The aetiology is still unclear; however, several major risk factors of HCC have been shown to contribute to hepatocarcinogenesis. Chronic inflammation induced by the action of various inflammatory mediators has been recently identified as a cofactor in carcinogenesis [3]. Among these inflammatory mediators, tumour necrosis factor- $\alpha$ (TNF- $\alpha$ ) plays an essential role and has been implicated in inflammationassociated tumours [4].

An "HCC Aggressiveness" scoring system was recently described, which incorporates four tumour-related parameters such as maximum tumour diameter (MTD), presence of portal vein thrombosis (PVT), number of lesions and serum alpha-fetoprotein (AFP) levels. The 
score was shown to predict survival in patients with HCC [5].

Aroucha et al. concluded that polymorphisms in TNF$\alpha$ and interleukin (IL)-10 were associated with increased risk of $\mathrm{HCC}$ development in $\mathrm{HCV}$ chronically infected patients. The GG genotype of TNF- $\alpha$ and genotypes associated with low/intermediate levels of IL-10 were shown to be associated with increased risk of development of HCC. Moreover, the TT genotype of the IL-10 -819 was significantly correlated with advanced stages of HCC as well as with multiplicity of lesions. These variants were shown to be associated with more inflammation in the liver, mediated by Th1 cytokines and may increase the risk to have HCC and bring an adverse prognosis in these patients [6].

\section{Aim of the study}

In this study, we tried to assess the association of TNF-a and IL-10 polymorphisms with the risk and aggressiveness of HCC in patients with HCV-related cirrhosis.

\section{Methods \\ Patients}

This is a case-control study that was conducted on 73 patients attending to early detection at HCC Clinic, Specialized Medical Hospital, Mansoura University, from June 2019 to February 2020 for follow-up of HCC and 85 patients with HCV-related cirrhosis without evidence of hepatic focal lesions proved by post-contrast triphasic computed tomography (CT) scan. Patients with cirrhosis related to other causes than $\mathrm{HCV}$, patients with any tumour outside the liver and patients with ongoing organ failure were excluded from the study. All patients were proved to be $\mathrm{HCV}$ infected through the history of previous antiviral treatment for $\mathrm{HCV}$ or through testing for HCV Ab or HCV RNA. All patients were exposed to complete history taking with stress on history of smoking or ex-smoker, diabetes, hypertension, history of previous treatment for $\mathrm{HCV}$ or bilharziasis and family history of cancer. Complete clinical examination was done for all patients with stress on manifestations of hepatocellular failure. Baseline tumour characters, including MTD, the number of focal lesions and the presence of portal vein thrombosis, were collected from imaging reports done at Specialized Medical Hospital for the HCC group.

\section{Laboratory assessment}

Complete blood count, liver function tests with ChildPugh classification, HBsAg, HCV Ab, serum creatinine and AFP were done for all patients.

\section{IL-10 and TNF-a polymorphism determination}

Peripheral blood was used to extract genomic DNA using the Wizard Genomic Blood DNA Isolation Kit (Promega, Madison, WI). We stored samples at $-80^{\circ} \mathrm{C}$ until single nucleotide polymorphism (SNP) genotyping by real-time polymerase chain reaction (PCR) was done. In IL-10 gene, we tested one substitution at position $-819 \mathrm{C}>\mathrm{T}$ (rs1800871). In TNF- $\alpha$, the substitution at position -308 G>A (rs1800629) was tested. We used TaqMan SNP Genotyping Assays (Applied Biosystems, Foster City, CA), according to the instructions of the manufacturer.

According to Ventura et al., the aggressiveness index (AgI) score was divided into three categories: a, score $<4$; b, $4<$ score $\leq 7$; and c, score $\geq 8$ (Table 1) [7].

Aggressiveness index was calculated for all patients with HCC. According to the result of genotype frequency distribution of IL-10 -819 (rs1800871) and TNF-a -308 (rs1800629), patients will be divided into groups and compared.

\section{Statistical analysis}

Data were fed to the computer and analysed using IBM SPSS Corp. (released in 2013, IBM SPSS Statistics for Windows, version 22.0, Armonk, NY: IBM Corp). Qualitative data were described using the number and per cent. Quantitative data were described using median and interquartile range for non-parametric data and mean, the standard deviation for parametric data after testing normality using the Kolmogorov-Smirnov test. The significance of the obtained results was judged at the 0.05 level.

Data analysis was done using the chi-square test and Monte Carlo test for comparison of 2 or more groups of categorical variables as appropriate. Student $t$ test and one-way ANOVA test were used to compare parametric variables. Mann-Whitney $U$ test and Kruskal-Wallis test were used to compare independent groups for nonparametric variables. Spearman's rank-order correlation is used to determine the strength and direction of a linear relationship between two non-normally distributed continuous variables and/or ordinal variables.

\section{Results}

\section{Patient sociodemographic characteristics}

The mean age of the HCC group was $56.21 \pm 4.62$ years and $54.27 \pm 7.63$ years for the cirrhotic group. There

Table 1 Aggressiveness index parameters

\begin{tabular}{llll}
\hline & 1 & 2 & 3 \\
\hline Maximum tumour dimension(CM) & $<4.5$ & $4.5-9.6$ & $>9.6$ \\
AFP $(\mathrm{ng} / \mathrm{ml})$ & $<100$ & $100-1000$ & $>1000$ \\
PVT & No & & Yes \\
Tumour nodule (number) & $\leq 3$ & & $>3$ \\
\hline
\end{tabular}


was no difference in sex distribution between the two groups. In the HCC group, 31 (42.5\%) patients had diabetes and 19 (26.0\%) hypertensive in comparison to 27 (31.8\%) and $23(27.1 \%)$ in the cirrhotic group, respectively. A statistically significant difference between the two groups was found as regards serum albumin, platelets, aspartate aminotransferase (AST) and AFP with $P=0.003,0.001,0.001$ and $<0.001$, respectively (Table 2).

\section{Genotype testing and distribution}

On genotype testing, as regards TNF-a, 35 (47.9\%) of patients were GG, 22 (30.1\%) were GA and 16 (21.9\%) were AA in the HCC group. In the cirrhotic group, 27 (31.8\%) of patients were GG, 25 (29.4\%) were GA and 33 (38.8\%) were AA. As regards IL-10, 29 (39.7\%) of patients were TT, 21 (28.8\%) were CT and 23 (31.5\%) were $\mathrm{CC}$ in the HCC group. In the cirrhotic group, 16 (18.8\%) of patients were TT, 29 (34.1\%) were CT and 40 (47.1\%) were $\mathrm{CC}$. From these data, it appears that the GG genotype of TNF-a and TT genotype of IL-10 showed a higher incidence of HCC in comparison to the cirrhotic group with $P=0.01$ and 0.004 (Table 3 and Fig. 1).

\section{Tumour characteristics and aggressiveness concerning genotype polymorphism}

As regards IL-10, the portal was found to be thrombosed significantly in the TT haplotype in contrast to the other haplotypes with $P<0.001$. Similarly, ascites was significantly found in the TT haplotype in contrast to the other haplotypes with $P=0.006$. On the other hand, there was no significant difference in the size of the spleen, lymph node metastases or site of the lesions between the haplotypes. On the calculation of the AgI, the TT haplotype was significantly associated with more aggressive tumours in contrast to the other haplotypes with $P<0.001$ (Table 4). Table 5 shows the tumour characteristics and aggressiveness of TNF-a genotypes where there was a significant association of portal vein thrombosis, ascites and high AgI with the GG haplotype in contrast to the other haplotypes with $P=0.002,0.029$

Table 2 Sociodemographic characteristics of the studied groups

\begin{tabular}{|c|c|c|c|}
\hline & $\mathrm{HCC}, n=73$ & Cirrhotic, $n=85$ & Test of significance \\
\hline Age/years, mean \pm SD & $56.21 \pm 4.62$ & $54.27 \pm 7.63$ & $\begin{array}{l}t=1.89 \\
P=0.06\end{array}$ \\
\hline \multicolumn{4}{|l|}{ Sex, $N(\%)$} \\
\hline Male & $43(58.9 \%)$ & $39(45.9 \%)$ & \multirow{2}{*}{$\begin{array}{l}x^{2}=2.67 \\
P=0.102\end{array}$} \\
\hline Female & $30(41.1 \%)$ & $46(54.1 \%)$ & \\
\hline $\mathrm{DM}, N(\%)$ & $31(42.5 \%)$ & $27(31.8 \%)$ & $\begin{array}{l}X^{2}=1.94 \\
P=0.164\end{array}$ \\
\hline Hypertension, $N(\%)$ & $19(26.0 \%)$ & $23(27.1 \%)$ & $\begin{array}{l}X^{2}=0.021 \\
P=0.884\end{array}$ \\
\hline Albumin $(\mathrm{gm} / \mathrm{dl})$, mean $\pm \mathrm{SD}$ & $3.29 \pm 0.59$ & $3.56 \pm 0.52$ & $\begin{array}{l}t=2.98 \\
P=0.003^{*}\end{array}$ \\
\hline Bilirubin (mg/dl), median (IQR) & $1.2(0.85-1.7)$ & $1.2(0.8-1.64)$ & $\begin{array}{l}z=0.821 \\
P=0.412\end{array}$ \\
\hline WBCS, mean \pm SD & $4.78 \pm 1.88$ & $4.69 \pm 1.85$ & $\begin{array}{l}t=0.33 \\
P=0.739\end{array}$ \\
\hline $\mathrm{HB}(\mathrm{gm} / \mathrm{dl})$, mean $\pm \mathrm{SD}$ & $11.33 \pm 1.66$ & $11.42 \pm 1.53$ & $\begin{array}{l}t=0.374 \\
P=0.709\end{array}$ \\
\hline Platelets $\times 10^{3}$, mean \pm SD & $101.05 \pm 44.17$ & $123.92 \pm 36.76$ & $\begin{array}{l}t=3.55 \\
P=0.001^{*}\end{array}$ \\
\hline $\operatorname{ALT}(\mathrm{U} / \mathrm{I})$, median (IQR) & $35.0(28.5-47.0)$ & $35.0(29.0-45.0)$ & $\begin{array}{l}z=0.452 \\
P=0.65\end{array}$ \\
\hline AFP (ng/dl), median (IQR) & $89.0(33.0-230.5)$ & $5.2(2.8-9.7)$ & $\begin{array}{l}z=9.98 \\
P<0.001^{*}\end{array}$ \\
\hline $\mathrm{AST}(\mathrm{U} / \mathrm{I})$, median (IQR) & $68.0(54.5-89.0)$ & $40.0(36.0-47.0)$ & $\begin{array}{l}z=7.67 \\
P<0.001^{*}\end{array}$ \\
\hline INR, mean $\pm S D$ & $1.36 \pm 0.20$ & $1.32 \pm 0.19$ & $\begin{array}{l}t=1.09 \\
P=0.275\end{array}$ \\
\hline
\end{tabular}

Parameters described as mean \pm SD, median (interquartile range) or number (percentage) $t$ Student $t$ test, $Z$ Mann-Whitney $U$ test, $X^{2}$ chi-square test

*Statistically significant 
Table 3 Genotype distribution among the studied groups

\begin{tabular}{|c|c|c|c|c|}
\hline & $\mathrm{HCC}, n=73(\%)$ & Cirrhotic, $n=85$ (\%) & Test of significance & Odds ratio $(95 \% \mathrm{Cl})$ \\
\hline \multicolumn{5}{|l|}{ IL-10 } \\
\hline TT/AA & $29(39.7 \%)$ & $16(18.8 \%)$ & \multirow{3}{*}{$\begin{array}{l}X_{2}^{2}=8.2, P=0.004^{*} \\
X^{2}=0.35, P=0.55\end{array}$} & $3.15(1.42-6.99)$ \\
\hline $\mathrm{CT} / \mathrm{CA}$ & $21(28.8 \%)$ & $29(34.1 \%)$ & & $1.26(0.59-2.69)$ \\
\hline $\mathrm{CC} / \mathrm{CC}$ & $23(31.5 \%)$ & $40(47.1 \%)$ & & Reference group \\
\hline Hardy-Weinberg equation & $P=0.002^{*}$ & $P=0.02^{*}$ & & \\
\hline \multicolumn{5}{|l|}{ TNF-a } \\
\hline GG & 35 (47.9\%) & $27(31.8 \%)$ & $x^{2}=6.24$ & $2.67(1.22-5.83)$ \\
\hline GA & $22(30.1 \%)$ & 25 (29.4\%) & $P=0.01^{*}$ & $1.82(0.79-4.15)$ \\
\hline AA & $16(21.9 \%)$ & $33(38.8 \%)$ & $X^{2}=2.01, P=0.16$ & Reference group \\
\hline Hardy-Weinberg equation & $P=0.002^{*}$ & $P=0.001^{*}$ & & \\
\hline
\end{tabular}

$x^{2}$ chi-square test

${ }^{*}$ Statistically significant

and $<0.001$, respectively. Table 6 shows the association of HCC aggressiveness index with sociodemographic and clinical characteristics and genotype of HCC cases where there was no statistically significant difference in the parameters except for AFP and genotype distribution as high $\mathrm{AgI}(\mathrm{C})$ was associated with the TT haplotype of IL-10 and GG haplotype of TNF-a.

\section{Discussion}

HCC represents about $90 \%$ or more of primary liver tumours that usually develops in a background of advanced liver disease [8]. Approximately, $10-20 \%$ of chronically infected patients with $\mathrm{HCV}$ will develop liver cirrhosis, and $1-5 \%$ of those patients will develop HCC [9]. The continued cytokines induced hepatocyte damage, and hepatocyte regeneration leads to HCC development. The role of cytokines as IL-1, IL-2, IL-6, IL-10, IL-12 and TNF- $\alpha$ in hepatocarcinogenesis has been reported. The management of patients with HCC represents a challenge as it is often complicated by the heterogenic pattern of the disease, the state of underlying liver disorders and the need to coordinate a multidisciplinary healthcare team [10].

In our study, the mean age of the HCC group was $56.21 \pm 4.62$ years and $54.27 \pm 7.63$ years for the cirrhotic group. There was no difference in sex distribution between the two groups (Table 2). In the HCC group, 31 (42.5\%) patients had diabetes and19 (26.0\%) hypertensive in comparison to $27(31.8 \%)$ and $23(27.1 \%)$ in the cirrhotic group, respectively. This runs parallel to many other studies that concluded that advanced age, male gender and DM are well-known risk factors for HCC [11]. Cirrhosis, due to HCV, was found in almost all our patients. This seems logical and in agreement with Seyda et al. who clarified that most of HCC cases develop in a background of cirrhosis [12]. There was no difference in the sociodemographic and clinicolaboratory parameters between the two groups except for serum albumin, platelets, AST and AFP with $P=0.003,0.001,0.001$ and $<0.001$, respectively. This seems logical as platelet count, AST and serum albumin reflect the severity of the liver disease. It also suggests that the two groups are

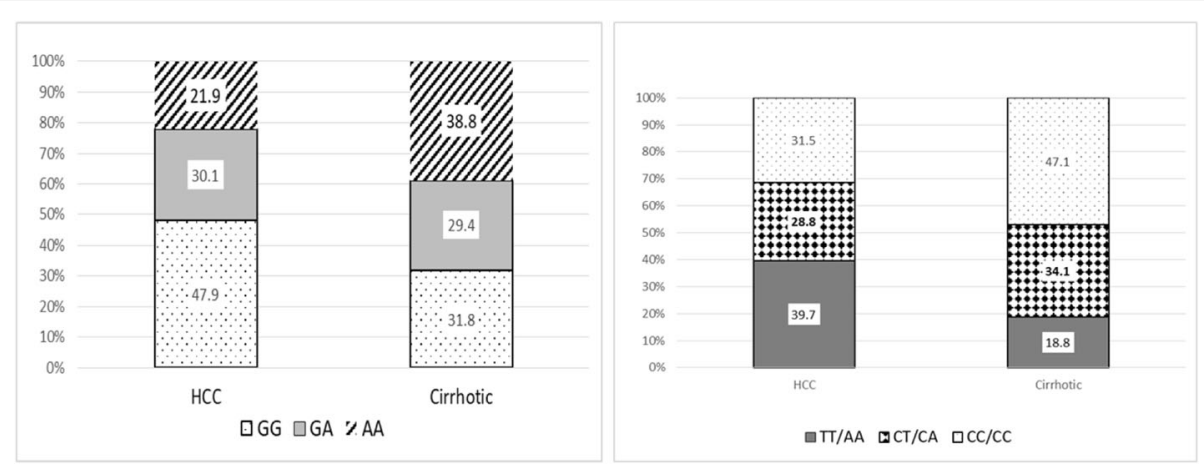

Fig. 1 Genotype distribution among the studied groups 
Table 4 Tumour characteristics of HCC cases according to IL-10 polymorphism

\begin{tabular}{|c|c|c|c|c|c|}
\hline & \multirow{2}{*}{$\begin{array}{l}\text { Total, } \\
n= \\
73\end{array}$} & \multicolumn{3}{|c|}{ Genotype } & \multirow{2}{*}{$\begin{array}{l}\text { Test of } \\
\text { significance }\end{array}$} \\
\hline & & TT/AA & $\mathrm{CT} / \mathrm{CA}$ & $\mathrm{CC} / \mathrm{CC}$ & \\
\hline \multicolumn{6}{|l|}{ Portal vein } \\
\hline Thrombosed & 10 & $10(34.5)$ & $0(0.0)$ & $0(0.0)$ & \multirow{2}{*}{$\begin{array}{l}M C \\
P<0.001^{*}\end{array}$} \\
\hline Patent & 63 & 19 (65.5) & $21(100.0)$ & $23(100.0)$ & \\
\hline \multicolumn{6}{|l|}{ Spleen } \\
\hline Splenectomy & 2 & $0(0.0)$ & $2(9.5)$ & $0(0.0)$ & \multirow{4}{*}{$\begin{array}{l}M C \\
P=0.154\end{array}$} \\
\hline Mild & 26 & $7(24.1)$ & $11(52.4)$ & $8(34.8)$ & \\
\hline Moderate & 39 & 19 (65.5) & $8(38.1)$ & $12(52.2)$ & \\
\hline Marked & 6 & $2(6.9)$ & $2(9.5)$ & $2(8.7)$ & \\
\hline \multicolumn{6}{|l|}{ Ascites } \\
\hline Negative & 62 & $20(69.0)$ & $19(90.5)$ & $23(100.0)$ & \multirow{2}{*}{$\begin{array}{l}M C \\
P=0.006^{*}\end{array}$} \\
\hline Positive & 11 & $9(31.0)$ & $2(9.5)$ & $0(0.0)$ & \\
\hline \multicolumn{6}{|l|}{ Lymph node } \\
\hline Negative & 64 & $23(79.3)$ & $21(100.0)$ & $20(87.0)$ & \multirow{2}{*}{$\begin{array}{l}M C \\
P=0.089\end{array}$} \\
\hline Positive & 9 & $6(20.7)$ & $0(0.0)$ & $3(13.0)$ & \\
\hline \multicolumn{6}{|l|}{$\mathrm{BCLC}$} \\
\hline A & 11 & $0(0.0)$ & 7 (33.3) & $4(17.4)$ & \multirow{4}{*}{$\begin{array}{l}M C \\
P<0.001^{*}\end{array}$} \\
\hline B & 24 & $3(10.3)$ & $7(33.3)$ & $14(60.9)$ & \\
\hline C & 24 & $13(44.8)$ & $7(33.3)$ & $4(17.4)$ & \\
\hline$D$ & 14 & $13(44.8)$ & $0(0.0)$ & $1(4.3)$ & \\
\hline \multicolumn{6}{|l|}{ Site of lesion } \\
\hline Right lobe & 25 & $10(34.5)$ & $6(28.6)$ & $9(39.1)$ & \multirow{3}{*}{$\begin{array}{l}M C \\
P=0.929\end{array}$} \\
\hline Left lobe & 12 & $5(17.2)$ & $3(14.3)$ & $4(17.4)$ & \\
\hline Multifocal & 36 & $14(48.3)$ & $12(57.1)$ & $10(43.5)$ & \\
\hline \multicolumn{6}{|l|}{$A G l$} \\
\hline A & 22 & $2(6.9)$ & $8(38.1)$ & $12(52.2)$ & \multirow{3}{*}{$\begin{array}{l}M C \\
P<0.001^{*}\end{array}$} \\
\hline B & 23 & $6(20.7)$ & $9(42.9)$ & $8(34.8)$ & \\
\hline C & 28 & $21(72.4)$ & $4(19.0)$ & $3(13.0)$ & \\
\hline
\end{tabular}

* means statistically significant

matched which is extremely important in the inclusion of our patients to avoid the effect of any factor such as age, sex or comorbidities on risk of HCC development, so the increased incidence of HCC is directly related to the effect of gene polymorphism.

In the present study, on genotype testing, as regards TNF-a, 35 (47.9\%) of patients were GG, 22 (30.1\%) were GA and $16(21.9 \%)$ were AA in the HCC group. In the cirrhotic group, 27 (31.8\%) of patients were GG, 25 (29.4\%) were GA and 33 (38.8\%) were AA. As regards IL-10, 35 (47.9\%) of patients were TT, 21 (28.8\%) were $\mathrm{CT}$ and 23 (31.5\%) were CC in the HCC group. In the cirrhotic group, $16(18.8 \%)$ of patients were TT, 29 (34.1\%) were CT and 40 (47.1\%) were CC. From these data, it appears that the GG genotype of TNF-a and TT genotype of IL-10 showed a higher incidence of HCC in comparison to the cirrhotic group with $P=0.01$ and 0.004 (Table 3 and Fig. 1). This goes hand in hand with Aroucha et al. who found that the TT/AT haplotypes of IL-10 and GG haplotype of TNF-a were significantly expressed in patients with HCC [6]. Wei et al. and Cheng et al. agreed [13, 14] also with us but not with Zhou et al. who showed that no association was found between HCC and the TNF- $\alpha-238 \mathrm{G} / \mathrm{A}$ polymorphism [15]. This contrast may be related to the aetiology of the underlying liver disease, ethnicity or number of included patients.

In 2012, Swiatek found that gene polymorphisms may affect the IL-10 level; he showed that IL-10 -819T was associated with significant low IL-10 expression since it is located in transcript factor binding regions [16]. Aroucha et al. observed an increased frequency of IL-10 -819T genotype in patients with HCC [6]. Moreover, they found a significant association between the TT genotype of IL-10 -819 and multiplicity of lesions and terminal stages of $\mathrm{HCC}$.

As regards TNF- $a$, the results are conflicting. Talaat et al. and Radwan et al. did not find any significant association between HCC and TNF-a -308 polymorphism in HCV-infected Egyptian patients [17, 18]. On the other hand, Baghel et al. and Karimi et al. demonstrated that patients with TNF-a G allele usually show low TNF-a production in vivo and in vitro $[19,20]$ despite, Vikram et al. failed to confirm this association [21]. It seems that the balance between IL-10 and TNF-a is crucial for the prevention of development of HCC and that low levels lead to progressive damage to the liver tissue and prevention of wound healing.

Similarly, previous studies found elevated levels of circulating TNF- $\alpha$ in patients with HCC. It is reasonable to speculate that in patients with $\mathrm{HCC}$, the high circulating TNF- $\alpha$ levels found may be attributed to its SNPs. Also, TNF- $\alpha$ may stimulate the release of other inflammatory cytokines and induce the release of other fibrogenic factors, such as interleukin-1, interleukin- 6 and tumour growth factor- $\beta$ which can cause or aggravate liver damage [22, 23].

Previously, immunomodulatory cytokines have been described as pre-malignant mediators in different tumour entities in different studies [24]. In HCC, IL-6 promotes multiple stages of tumour development, including initial hepatocyte proliferation, the transformation of hepatocytes into HCC progenitor cells, and progression to HCC nodules and metastases [24].

It seems that the balance between TNF-a and IL-10 is mandatory to the development of $\mathrm{HCC}$, since the shift to Th1 pattern-like cytokines in the liver may lead to more inflammation, necrosis of hepatocytes and subsequent regeneration that leads to mutagenesis and 
Table 5 Tumour characteristics of HCC cases according to TNF-a polymorphism

\begin{tabular}{|c|c|c|c|c|c|}
\hline & \multirow[b]{2}{*}{ Total, $n=73(\%)$} & \multicolumn{3}{|l|}{ Genotype } & \multirow{2}{*}{$\begin{array}{l}\text { Test of } \\
\text { significance }\end{array}$} \\
\hline & & $\overline{G G}$ & GA & $\mathrm{AA}$ & \\
\hline \multicolumn{6}{|l|}{ Portal vein } \\
\hline Thrombosed & 10 & 10 (28.6) & $0(0.0)$ & $0(0.0)$ & \multirow{2}{*}{$\begin{array}{l}M C \\
P=0.002^{*}\end{array}$} \\
\hline Patent & 63 & $25(71.4)$ & $22(100.0)$ & $16(100.0)$ & \\
\hline \multicolumn{6}{|l|}{ Spleen } \\
\hline Splenectomy & 2 & $0(0.0)$ & $2(9.1)$ & $0(0.0)$ & \multirow{4}{*}{$\begin{array}{l}M C \\
P=0.313\end{array}$} \\
\hline Mild & 26 & $14(40.0)$ & $8(36.4)$ & $4(25.0)$ & \\
\hline Moderate & 39 & $18(51.4)$ & $12(54.5)$ & $9(56.2)$ & \\
\hline Marked & 6 & $2(5.7)$ & $2(9.1)$ & $2(12.5)$ & \\
\hline \multicolumn{6}{|l|}{ Ascites } \\
\hline Negative & 62 & $26(74.3)$ & $22(100.0)$ & $14(87.5)$ & \multirow{2}{*}{$\begin{array}{l}M C \\
P=0.029^{*}\end{array}$} \\
\hline Positive & 11 & $9(25.7)$ & $0(0.0)$ & $2(12.5)$ & \\
\hline \multicolumn{6}{|l|}{ Lymph node } \\
\hline Negative & 64 & $28(80.0)$ & $22(100.0)$ & $14(87.5)$ & \multirow{2}{*}{$\begin{array}{l}M C \\
P=0.08\end{array}$} \\
\hline Positive & 9 & $7(20.0)$ & $0(0.0)$ & $2(12.5)$ & \\
\hline \multicolumn{6}{|l|}{$\mathrm{BCLC}$} \\
\hline A & 11 & $0(0.0)$ & $5(22.7)$ & $6(37.5)$ & \multirow{4}{*}{$\begin{array}{l}M C \\
P<0.001^{*}\end{array}$} \\
\hline B & 24 & $2(5.7)$ & $15(68.2)$ & $7(43.8)$ & \\
\hline C & 24 & $19(54.3)$ & $2(9.1)$ & $3(18.8)$ & \\
\hline D & 14 & $14(40.0)$ & $0(0.00)$ & $0(0.0)$ & \\
\hline \multicolumn{6}{|l|}{ Site of lesion } \\
\hline Right lobe & 25 & $12(34.3)$ & $9(40.9)$ & $4(25.0)$ & \multirow{3}{*}{$\begin{array}{l}M C \\
P=0.74\end{array}$} \\
\hline Left lobe & 12 & $7(20.0)$ & $2(9.1)$ & $3(18.8)$ & \\
\hline Multifocal & 36 & $16(45.7)$ & $11(50.0)$ & $9(56.2)$ & \\
\hline \multicolumn{6}{|l|}{ AGl } \\
\hline A & 22 & $0(0.0)$ & $12(54.5)$ & $10(62.5)$ & \multirow{3}{*}{$\begin{array}{l}M C \\
P<0.001^{*}\end{array}$} \\
\hline B & 23 & $9(25.7)$ & $8(36.4)$ & $6(37.5)$ & \\
\hline C & 28 & $26(74.3)$ & $2(9.1)$ & $0(0.0)$ & \\
\hline
\end{tabular}

* means statistically significant

activation of protooncogene in the host cells, leading to the development of HCC [25].

A fine tune of the IL-10 and TNF-a balance may exist, and it looks that this balance is controlled by the level of IL-10, where low levels lead to progressive damage to liver tissue and prevention of wound healing. Also, IL-10 can diminish the response to antiviral treatment [26].

Our data showed that the TT haplotype of IL-10 was significantly associated with more aggressive tumours in contrast to the other haplotypes with $P<$ 0.001 . The portal was found to be thrombosed significantly in the TT haplotype in contrast to the other haplotypes with $P<0.001$; they were also associated with the multiplicity of lesions. Similarly, a significant association of portal vein thrombosis, ascites and high AgI with the GG haplotype in contrast to the other haplotypes with $P=0.002,0.029$ and $<0.001$, respectively. These data are available in the absence of a statistically significant difference between AgI and sociodemographic and clinicolaboratory characteristics except for AFP and genotype distribution. This suggests that the aggressive pattern of the tumour noticed in these haplotypes is related to the direct effect of gene polymorphism. Aroucha et al. agree with us as they observed a significant correlation of advanced stages and multiple lesions of HCC with the TT (AA) genotype of IL-10 -819 (-592) [6]. However, studies covering this sector are relatively rare.

Our study may be limited by some factors such as the limited number of cases in the study, the lack of data about overall survival of patients and lastly we included only patients with $\mathrm{HCV}$-related cirrhosis which may affect hepatocarcinogenesis. 
Table 6 Association of HCC aggressiveness index with sociodemographic and clinical characteristics and genotype of HCC cases

\begin{tabular}{|c|c|c|c|c|}
\hline & \multicolumn{3}{|l|}{ AGI } & \multirow{2}{*}{$\begin{array}{l}\text { Test of } \\
\text { significance }\end{array}$} \\
\hline & $A$ & $B$ & C & \\
\hline Age/years, mean \pm SD & $54.64 \pm 4.44$ & $57.74 \pm 4.98$ & $56.18 \pm 4.15$ & $\begin{array}{l}F=2.66 \\
P=0.08\end{array}$ \\
\hline \multicolumn{5}{|l|}{ Sex, $n(\%)$} \\
\hline Male & $13(59.1)$ & $15(65.2)$ & $15(53.6)$ & \multirow{2}{*}{$\begin{array}{l}X^{2}=0.708 \\
P=0.702\end{array}$} \\
\hline Female & $9(40.9)$ & $8(34.8)$ & $13(46.4)$ & \\
\hline Albumin $(\mathrm{g} / \mathrm{dl})$, mean $\pm \mathrm{SD}$ & $3.36 \pm 0.62$ & $3.23 \pm 0.71$ & $3.28 \pm 0.46$ & $\begin{array}{l}F=0.280 \\
P=0.757\end{array}$ \\
\hline Bilirubin (mg/dl), median (IQR) & $1.1(0.90-1.7)$ & $1.68(0.80-2.4)$ & $1.20(0.825-1.5)$ & $\begin{array}{l}\text { KW } \\
P=0.514\end{array}$ \\
\hline WBCS, mean \pm SD & $5.25 \pm 1.89$ & $4.40 \pm 1.21$ & $4.72 \pm 2.28$ & $\begin{array}{l}F=1.15 \\
P=0.32\end{array}$ \\
\hline $\mathrm{HB}(\mathrm{g} / \mathrm{dl})$, mean $\pm \mathrm{SD}$ & $11.88 \pm 1.43$ & $10.91 \pm 1.56$ & $11.24 \pm 1.84$ & $\begin{array}{l}F=1.15 \\
P=0.32\end{array}$ \\
\hline Platelet ${ }^{*} 10^{3}$, mean $\pm S D$ & $85.09 \pm 29.89$ & $116.09 \pm 56.5$ & $101.25 \pm 38.8$ & $\begin{array}{l}F=2.92 \\
P=0.061\end{array}$ \\
\hline ALT (u/l), median (IQR) & $38.0(27.0-43.0)$ & $36.0(32.0-55.0)$ & $33.0(29.25-65.75)$ & $\begin{array}{l}\mathrm{KW} \\
P=0.482\end{array}$ \\
\hline AFP (ng/dl), median (IQR) & $190(83.0-536.0)^{\mathrm{a}}$ & $83.0(27.0-340.0)$ & $67.0(32.0-106.25)^{a}$ & $\begin{array}{l}\mathrm{KW} \\
P=0.013^{*}\end{array}$ \\
\hline $\operatorname{AST}(\mathrm{U} / \mathrm{l})$, median (IQR) & $56.0(47.0-88.0)$ & $69.0(66.0-89.0)$ & $71.0(53.0-98.0)$ & $\begin{array}{l}\mathrm{KW} \\
P=0.09\end{array}$ \\
\hline INR, mean $\pm S D$ & $1.36 \pm 0.13$ & $1.41 \pm 0.29$ & $1.31 \pm 0.15$ & $\begin{array}{l}F=1.71 \\
P=0.189\end{array}$ \\
\hline $\mathrm{DM}, n(\%)$ & $8(36.4)$ & $9(39.1)$ & $14(50.0)$ & $P=0.58$ \\
\hline Hypertension, $n$ (\%) & $6(27.3)$ & $6(26.1)$ & $7(25.0)$ & $P=0.98$ \\
\hline \multicolumn{5}{|l|}{ IL-10 genotypes } \\
\hline TT/AA & $2(9.1)^{a}$ & $6(26.1)^{b}$ & $21(75.0)^{a, b}$ & \multirow{3}{*}{$\begin{array}{l}M C \\
P<0.001^{*}\end{array}$} \\
\hline $\mathrm{CT} / \mathrm{CA}$ & $8(36.4)$ & $9(39.1)$ & $4(14.3)$ & \\
\hline $\mathrm{CC} / \mathrm{CC}$ & $12(54.5)$ & $8(34.8)$ & $3(10.7)$ & \\
\hline \multicolumn{5}{|l|}{ TNF-a genotypes } \\
\hline GG & $0(0.0)^{a, b}$ & $9(39.1)^{a, c}$ & $26(92.9)^{\mathrm{b}, \mathrm{c}}$ & \multirow{3}{*}{$\begin{array}{l}M C \\
P<0.001^{*}\end{array}$} \\
\hline GA & $12(54.5)$ & $8(34.8)$ & $2(7.1)$ & \\
\hline$A A$ & $10(45.5)$ & $6(26.1)$ & $0(0.0)$ & \\
\hline
\end{tabular}

MC Monte Carlo test, KW Kruskal-Wallis test, $F$ one-way ANOVA test

* means statistically significant

a significance with group a

b significance with group $b$

c significance with group $c$

ab significance with group $a, b$

bc significance with group b, $c$

To summarize, specific genotypes of TNF-a and IL-10 may affect the progression of hepatocarcinogenesis in patients with HCV-related liver cirrhosis.

\section{Conclusion}

Our data bring an essential association of IL-10 and TNF polymorphism with the occurrence of HCC in HCV-related liver cirrhosis. The GG haplotype of TNF$\mathrm{a}$ and TT/AT haplotype of IL-10 are associated with the more aggressive pattern of HCC, so those patients must be treated as early as possible.

\section{Abbreviations}

HBV: Hepatitis B virus; HCV: Hepatitis C virus; HCC: Hepatocellular carcinoma; TNF-a: Tumour necrosis factor-a; MTD: Maximum tumour diameter; PVT: Portal vein thrombosis; AFP: Alpha-fetoprotein; IL: Interleukin; $C T$ : Computed tomography; PCR: Polymerase chain reaction; SNP: Single nucleotide polymorphism; Agl: Aggressiveness index; AST: Aspartate aminotransferase; ALT: Alanine aminotransferase 


\section{Acknowledgements}

The authors would like to thank all patients who participated in the study.

\section{Authors' contributions}

AA: choosing the idea, patient examination, writing and reviewing. AM: patient examination, writing and reviewing. MM: genotype testing. All authors have read and approved the final manuscript.

\section{Funding}

Nil.

\section{Availability of data and materials}

Available at the data archive at Specialized Medical Hospital, Faculty of Medicine, Mansoura University, Egypt

\section{Ethics approval and consent to participate}

Written consents from patients who participated in the study or from their families were obtained and approved by Mansoura Medical Ethics Committee (MMEC) of Faculty of Medicine. Code: R.19.01.411

\section{Consent for publication}

NA

\section{Competing interests}

There are no conflicts of interest.

\section{Author details}

${ }^{1}$ Department of Internal Medicine, Hepatology \& Gastroenterology unit, Faculty of Medicine, Mansoura University, Mansoura, Egypt. ${ }^{2}$ Specialized Medical Hospital, Faculty of Medicine, Mansoura University, Mansoura, Egypt. ${ }^{3}$ Department of Clinical Pathology, Faculty of Medicine, Mansoura University, Mansoura, Egypt.

Received: 8 May 2020 Accepted: 18 August 2020

Published online: 01 September 2020

\section{References}

1. Averhoff FM, Glass N, Holtzman D (2012) Global burden of hepatitis C: considerations for health-care providers in the United States. Clin Infect Dis 55(S1):S10-S15

2. Waly Raphael S, Yangde Z, Yuxiang C (2012) Hepatocellular carcinoma: focus on different aspects of management. ISRN Oncol:421673.

3. Yang JD, Roberts LR (2010) Epidemiology and management of hepatocellular carcinoma. Infect Dis Clin N Am 24(4):899-919

4. Yoshimura A (2006) Signal transduction of inflammatory cytokines and tumour development. Cancer Sci 97:439-447

5. Carr Bl, Guerra V (2016) A hepatocellular carcinoma aggressiveness index and its relationship to liver enzyme levels. Oncology 90:215-220

6. Aroucha DC, Carmo RF, Vasconcelos LR et al (2016) TNF-a and IL-10 polymorphisms increase the risk to hepatocellular carcinoma in HCV infected individuals. J Med Virol 88:1587-1595

7. Ventura N, Carr BI, Kori I, Guerra V, Shibolet O (2018) Analysis of aggressiveness factors in hepatocellular carcinoma patients undergoing transarterial chemoembolization. World J Gastroenterol 24(15):1641-1649

8. EASL-EORTC clinical practice guidelines (2012) management of hepatocellular carcinoma. J Hepatol 56:908-943

9. Shire NJ, Sherman KE (2015) Epidemiology of hepatitis C virus: a battle on new frontiers. Gastroenterol Clin N Am 44(699):716

10. National Comprehensive Cancer Network: NCCN clinical practice guidelines in oncology. Hepatobiliary Cancers. Version 3. 2017.

11. Westbrook RH, Dusheiko G (2014) Natural history of hepatitis C. J Hepatol 61:S58-S68

12. Seyda Seydel G, Kucukoglu O, Altinbasv A, Demir OO, Yilmaz S, Akkiz H, Otan E, Sowa JP, Canbay A (2016) Economic growth leads to increase of obesity and associated hepatocellular carcinoma in developing countries. Ann Hepatol 15:662-672

13. Wei $Y$ et al (2011) Polymorphisms of tumour necrosis factor-alpha and hepatocellular carcinoma risk: a HuGE systematic review and meta-analysis. Dig DisSci 56:2227-2236
14. Cheng K et al (2013) Tumour necrosis factor-alpha 238G/A polymorphism and risk of hepatocellular carcinoma: evidence from a meta-analysis. Asian Pac J Cancer Prev 14:3275-3279

15. Zhou P et al (2011) The TNF-alpha-238 polymorphism and cancer risk: ameta- analysis. PLoS One 6:e22092

16. Swiatek BJ (2012) Is interleukin-10 gene polymorphism a predictive marker in HCV infection? Cytokine Growth Factor Rev 23:47-59

17. Talaat RM, Esmail AA, Elwakil R, Gurgis AA, Nasr MI (2012) Tumour necrosis factor-alpha 308G/A polymorphism and risk of hepatocellular carcinoma in hepatitis C virus-infected patients. Chin J Cancer 31:29-35

18. Radwan Ml, Pasha HF, Mohamed RH, Hussien HI, El-Khshab MN (2012) Influence of transforming growth factor-b1 and tumour necrosis factor-a genes polymorphisms on the development of cirrhosis and hepatocellular carcinoma in chronic hepatitis C patients. Cytokine 60:271-276

19. Baghel K, Srivastava RN, Chandra A, Goel SK, Agrawal J, Kazmi HR, Raj S (2014) TNF-a, IL-6, and IL-8 cytokines and their association with TNF-a -308 G/A polymorphism and postoperative sepsis. J Gastrointest Surg 18:1486-1494

20. Karimi M, Goldie LC, Cruickshank MN, Moses EK, Abraham LJ (2009) A critical assessment of the factors affecting reporter gene assays for promoter SNP function: a reassessment of -308 TNF polymorphism function using a novel integrated reporter system. Eur J Hum Genet 17:1454-1462

21. Vikram NK, Bhatt SP, Bhushan B, Luthra K, Misra A, Poddar PK, Pandey RM, Guleria R (2011) Associations of -308G/A polymorphism of tumor necrosis factor (TNF)-a gene and serum TNF-a levels with measures of obesity, intraabdominal and subcutaneous abdominal fat, subclinical inflammation and insulin resistance in Asian Indians in north India. Dis Markers 31:39-46

22. Morsi Ml et al (2006) Evaluation of tumour necrosis factor-alpha, soluble Pselectin, gamma-glutamyl transferase, glutathioneS-transferase-p and alpha fetoprotein in patients with hepatocellular carcinoma before and during chemotherapy. Br J Biomed Sci 63:74-78

23. Wang YY et al (2003) Increased serum concentrations of tumour necrosis factor-alpha are associated with disease progression and malnutrition in hepatocellular carcinoma. J Chin Med Assoc 66:593-598

24. Schmidt-Arras D, Rose-John S (2016) IL-6 pathway in the liver: from physiopathology to therapy. J Hepatol 64:1403-1415

25. Bouzgarrou N, Hassen E, Farhat K, Bahri O, Gabbouj S, Maamouri N, Ben Mami N, Saffar H, Trabelsi A, Triki H, Chouchane L (2009) Combined analysis of interferon-gamma and interleukin-10 gene polymorphisms and chronic hepatitis C severity. Hum Immunol 70:230-236

26. Coussens LM, Werb Z (2002) Inflammation and cancer. Nature 420:860-867

\section{Publisher's Note}

Springer Nature remains neutral with regard to jurisdictional claims in published maps and institutional affiliations.

\section{Submit your manuscript to a SpringerOpen ${ }^{\circ}$ journal and benefit from:}

- Convenient online submission

- Rigorous peer review

- Open access: articles freely available online

High visibility within the field

Retaining the copyright to your article

Submit your next manuscript at $>$ springeropen.com 